\title{
Frequency and Types of Parapneumonic Effusion in Pleural Fluid Specimen
}

\author{
Mohammad Sajjad', Naseeb ur Rehman Shah², Sami Ullah Khan², Asim Muhammad', \\ Shabir Hussain ${ }^{3}$, Rafi Ullah ${ }^{4}$
}

\begin{abstract}
Background: Parapneumonic effusion (PPE) is exudative pleural effusion resulting from community acquired pneumonia or lung abscess. In USA about one million people develop PPE annually. The better outcome of PPE depends on early diagnosis and timely management.

Objective: The aim of this study was to see the frequency and types of parapneumonic effusion in pleural fluid specimen using different laboratory parameters in pneumonia patients.

Material and Methods: This study was conducted in Shah Noor Medical laboratory in Bannu KPK. Pakistan. Pleural fluid specimen were collected from both public and private sectors hospitals of the territory. A total of 422 pleural effusions were collected. These fluid were analysed for transudate, exudate with possible causes. The PPE were subtyped into simple, complicated and empyema on the basis of color, $\mathrm{PH}$ value, ratio of blood and fluid glucose level, total protein level, total and differential leukocyte count of fluid, Gram's stain and culture for presence or absence of bacteria. The pleural fluid color was examined for subjective grades of turbidity i.e. mild, moderate and marked for simple, complicated and empyema respectively. PH cut off value was 7.2 for simple and complicated PPE, glucose cut off value of $52 \mathrm{mg} / \mathrm{dl}$ for simple and complicated PPE. Gram's stain and culture was performed by using conventional Gram's stain and different culture media for differention of simple from complicated PPE and emyema. Inclusion criteria was all pleural effusions either exudative or transudative. Exclusion criteria was insufficient pleural fluid. The data was collected and analysed for frequencies with percentages and mean with standard deviation using SPSS version 20.
\end{abstract}

Results: In this study a total of 422 pleural fluid out of which 77(18.24\%) PPE cases were analysed. The age range was from 11-80 years with mean age of 54.34 \pm 9.22 years. Amongst these PPE 41 were from males patients and 36 from female patients. Simple PPE were 21(27.30\%), complicated PPE 37(48.05\%) and empyema were 29(37.7\%).

Conclusion: The laboratory parameters for differentiation of different types of parapneumonic effusion have significant role in differentiation and management of different types of PPE and must be analysed in laboratory to separate the subtypes and guide the physician about using non invasive and invasive management modalities.

Key words: Parapneumonic effusion. Community acquired pneumonia. Empyema thoracis. Simple and complicated parapneumonic effusion.

This article may be cited as: Sajjad M, Shah RN, Khan US, Muhammad A, Hussain S, Ullah R

Frequency and types of parapneumonic effusion in pleural fluid specimen. J Saidu Med. Coll. Swat 2020;10(1):31-34

\section{INTRODUCTION}

Parapneumonic effusion (PPE) is pleural effusion which occurs as complication of pneumonia and is the common cause of infection related mortality. About $40 \%$ of hospitalized patients of pneumonia develop PPE in due course of time. Parapneumonic effusion is defined as the collection of exudative pleural effusion in pleural space as a complication of community acquired pneumonia, lung abscess, broncheictasis etc. PPE progresses through a series of compositional changes leading to simple, complicated PPE and empyema thoracis. ${ }^{1}$

There are three types of PPE simple, complicated and empyema. In simple PPE the fluid is clear to mild turbid, $\mathrm{PH}>7.2$, contain no bacteria and is

\section{Pathology Department, Bannu Medical College Bannu \\ 2. Medicine Department, Khalifa Gul Nawaz Teaching Hospital Bannu \\ 3. Pharmacologyy Department, Bannu Medical College Bannu \\ 4. Surgery Deptt. Khalifa Gul Nawaz Teaching Hospital Bannu, KPK.}

Correspondence: Dr. Muhammad Sajjad

Pathology Department, Bannu Medical College Bannu

Email: sajjadkhattak66@gmail.com usually treated with antibiotic like pneumonia. ${ }^{2}$ In complicated PPE fluid show moderate turbidity, presence of bacteria on Gram's stain or culture, $\mathrm{PH}<7.2$ and fluid glucose level less than 60 $\mathrm{mg} / \mathrm{dl}$. These complicated PPE patients needs complete drainage in addition to antibiotic treatment. In empyema thoracis frank pus is present in pleural cavity, needs chest intubation drainage and antibiotics treatment. ${ }^{3}$

The pathogenesis of parapneumonic effusions is due to increased interstitial fluid pressure in lungs during pneumonia resulting in oozing of protein rich fluid from lung parenchyma to pleural cavity followed by inflammatory cells especially neutrophils. ${ }^{4}$ Parapneumonic effusion have significant morbidity and mortality in cases of delayed management. Integrity of pleural mesothelial cells play an important role in maintenance of pleural barrier. The mesothelial cells are in tight junction with each other through intercellular adhesion molecules proteins called adherens responsible for maintaining pleural mesothelial barrier function. Bacteria causes breaches in mesothelial cells integrity resulting in formation of gaps leading to leakage of fluid, 
protein and inflammatory cells into the pleural space. ${ }^{5} \quad$ Factors that regulate this process is unclear. It is postulated that an enzyme Heme Oxygenase $(\mathrm{HO})$ concentration is increased in pleural fluid during inflammation and is considered a possible stress induced enzyme leading to regulation of permeability of pleural fluid. ${ }^{6,7}$

The aim of this study was to see the frequency of PPE and separation of different subtypes of PPE by using different conventional laboratory tests and to provide a guideline about use of management modality by attending physician.

\section{MATERIALAND METHODS}

This study was conducted in a Shah Noor laboratory in Bannu KPK. Pakistan. The pleural fluid specimen were collected from various public and private sector hospitals of the territory. The duration of this study was one year (from January, 2017 to December, 2017). Inclusion criteria was all cases of pleural effusion of any age and sex. Exclusion criteria was incomplete clinical information and insufficient quantity of Pleural Fluid. Fluid examination was performed soon after collection. The pleural fluid of PPE were subtyped into simple, complicated and empyema on the basis of color, $\mathrm{PH}$ value of fluid, fluid glucose, total protein and LDH levels, fluid total leukocyte count, Gram's stain and culture. The fluid color was examined for subjective grades of turbidity i.e. mild, modrate and frank pus in simple, complicated and empyema respectively. $\mathrm{PH}$ cut off value was 7.2 for simple and complicated PPE. The PH meter used was model PHS 3BW, made by Bante instrument co. Itd, USA. Fluid glucose level cut off value was $52 \mathrm{mg} / \mathrm{dl}$ for simple and complicated PPE. Total fluid protein of $2.5 \mathrm{gm} / \mathrm{dl}$ was used as cut off value for separation of transudate from exudate. The kits used for measurement of glucose nas total protein was Innoline (France) and the chemistry analyzer used was Microlab 400. Total leukocyte count cut off value was $15000 / \mathrm{cmm}$ for simple and complicated PPE. TLC count was performed by using Sysmix Hematology analyzer, where as fluid Gram's stain and culture was performed by using conventional Gram's stain and culture media like Blood Agar, Nutrient Agar and Mackonky. Both Gram's stain and culture were negative in simple PPE and was positive in complicated PPE. The data were analysed statistically by using SPSS version 20 for frequency with percentages and mean with standard deviation.

\section{RESULTS}

In this study a total of 422 pleural effusion were analysed. Amongst these 77 cases were PPE. The age range was from 11-80 years with mean age of $54.34 \pm 9.22$ years. Amongst the PPE's 41 cases were from males and 36 from female patients. The frequency of PPE was $18.24 \%$. Simple PPE were 21(27.30\%), complicated PPE 37(48.05\%) and empyema thoracis were $29(37.7 \%)$.

Table I. Frequency of PPE amongst pleural effusion specimen. ( $n=422)$.

\begin{tabular}{|c|c|c|}
\hline Type of pleural effusion & No. of pleural effusion & Percentage \\
\hline Parapneumonic effusion & 77 & $18.25 \%$ \\
\hline Other pleural effusion & 345 & $81.75 \%$ \\
\hline Total & 422 & $100 \%$ \\
\hline
\end{tabular}

Table II. Frequency of different types of parapneumonic effusion. $(n=77)$.

\begin{tabular}{|c|c|c|}
\hline Type of effusion & No. of Effusion & Percentages \\
\hline Simple PPE & 21 & $27.30 \%$ \\
\hline Complicate PPE & 37 & $48.05 \%$ \\
\hline Empyema & 29 & $37.70 \%$ \\
\hline Total & 77 & $100 \%$ \\
\hline
\end{tabular}

Table III. Laboratory parameters used for separation of types of PPE.

\begin{tabular}{|c|c|c|c|}
\hline Lab test & Simple PPE & Complicated PPE & Empyema \\
\hline Fluid color & Mild turbidity & Cloudy & Pus \\
\hline PH value & $>7.2$ & $<7.2$ & $\mathrm{NA}$ \\
\hline Fluid glucose level & $>60 \mathrm{mg} / \mathrm{dl}$ & $<60 \mathrm{mg} / \mathrm{dl}$ & $\mathrm{NA}$ \\
\hline LDH level & $<700 \mathrm{u} / \mathrm{l}$ & $>1000 \mathrm{u} / \mathrm{l}$ & $\mathrm{NA}$ \\
\hline TLC count & $<15,000 / \mathrm{cmm}$ & $>25,000 / \mathrm{cmm}$ & $\mathrm{NA}$ \\
\hline & Negative in all cases & $65 \%$ Posittive & $100 \%$ positive \\
\hline
\end{tabular}




\section{DISCUSSION}

Parapneumonic effusion is classified into three categories i.e. simple (uncomplicated), complicated and frank empyema thoracis. All these are continuation of disease spectrum related to prolongation of course of pbeumonia. This traditional classification is used for management purposes based on lab results to treat patient conservatively or using chest intubation for drainage with additional antibiotic treatment. $^{8}$ In simple PPE conservative therapy with antibiotic is required, where as in complicated PPE usually pleural intubation is required to prevent progression to empyema, also the same is required in empyema with aggressive antibiotic therapy, where more chances of complications can exist. ${ }^{9}$

The laboratory parameters used to differentiate different types of PPE depends on gross appearance of fluid, $\mathrm{PH}$ value, fluid chemistry and culture. In case of empyema on gross and microscopy chemistry is usually not required, only cell count and their differential count is required to label the fluid as empayema. The most important is differentiation between simple and complicated PPE. This is based on various laboratory parameters. The common parameters used are gross appearance, $\mathrm{PH}$ value, fluid glucose level in case of non diabetic patients, Gram's stain and culture. $^{10}$

In simple PPE where $\mathrm{PH}$ value is $>7.2$, fluid glucose is $>52 \mathrm{mg} / \mathrm{dl}$. Fluid neutrophils count is $<15000 / \mathrm{cmm}$ and fluid Gram's stain and culture is negative. The clinician usually preferr conservative treatment instead of chest intubation. In complicated PPE the fluid $\mathrm{PH}$ value is $<7.2$, glucose is $<52 \mathrm{mg} / \mathrm{dl}$. neutrophils count is $>15000 / \mathrm{cmm}$ and culture may be positive/negative, chest intubation is usually required in such cases. ${ }^{11}$

In this study the age range is from 11-80 years with mean age of $54.34 \pm 9.22$ years. Male to female ratio is $1.13: 1$. In a study conducted by Porcel et $\mathrm{al}^{11}$ in 2006 the mean age was $57 \pm 20$ years and male to female ratio was 2.38:1.

The frequency of PPE amongst pleural effusion was $18.24 \%$. In study conducted by Sonali et al $^{12}$ in India in 2013 the frequency of PPE was $17.7 \%$. A study conducted by Mohanty et $\mathrm{al}^{13}$ in India in 2007 the frequency was $15.3 \%$. Another study conducted by Ferrer et al $^{14}$ in West in 1999 was $15.5 \%$. In a study conducted by Falguera et $\mathrm{al}^{15}$ in 2011 the frequency of PPE was 19\%. Another study conducted by Marinkovec et $\mathrm{al}^{16}$ in 2016 parapneumonic effusion was recorded in $23.18 \%$ of cases. The frequency of different pattern of PPE depends upon multiple factors like presentation of disease, stage of disease treatment etc.

\section{CONCLUSION}

The laboratory parameters for differentiation of various subtypes of parapneumonic effusion have significant role in management of different types of PPE and must be addressed to separate the subtypes of PPE for providing guide line about use of non invasive and invasive management modalities.

\section{RECOMMENDATION}

It is recommended to use additional supportive investigation like X-Ray chest, ultrasound studies to exclude multiloculation of PPE, bilaterality, volume of PPE and culture sensitivity of bacteria in addition to conventional laboratory investigation for separation PPE subtypes.

\section{REFERENCES}

1. Ferreiro L, Toubes ME, Valdés L. Contribution of pleural fluid analysis to the diagnosis of pleural effusion. Med Clin (Barc) 2015;145:171-7.

2. Maikap MK, Dhua A, Maitra MK. Etiology and clinical profile of pleural effusion. Int J Med Sci Public Health 2018;7(4):316-21.

3. Davies HE, Davies RJ, Davies CWH. Management of pleural infection in adults: British Thoracic Society pleural disease guideline2010. Thorax 2010;65:4153.

4. Colice GL, Curtis A, Deslauriers J, Hefner J, Light RW, Littenberg B, et al. Medical and surgical treatment of parapneumonic effusions: An evidencebased guideline. Chest 2000;118:1158.

5. Wrightson JM, Davies RJ. The approach to the patient with a parapneumoniceffusion. Semin Respir Crit Care Med 2010;31:706-15.

6. Rahman NM. Intrapleural agents for pleural infection: Fibrinolytics and beyond. Curr Opin Pulm Med 2012;18:326-32.

7. Mohan KM, Ravindran C. Etiology and clinical profile of pleural effusion in a teaching hospital of South India: A descriptive study. Pulmon 2012;14:89-96.

8. Akulian J, Feller-Kopman D. The past, current and future of diagnosis and management of pleural disease. J Thorac Dis 2015;7:S329-38.

9. Fine MJ, Auble TE, Yealy DM, Hanusa BH, Weissfold LA, Singer DE. Et al. A prediction rule to identify low risk patients with community acquired pneumonia. JAMA 1996;275:134-41.

10. Karkhanis VS, Joshi JM. Pleural effusion: Diagnosis, treatment, and management. Open Access Emerg Med 2012;4:31-52. 
11. Porcel JM. Distinguishing complicated from uncomplicated Parapneumonic effusions. Current Opinion 2015;21(4):346-51.

12. Sonali J, Banavaliker JN. Empyema thoracis:Bacteriological analysis of pleural fluid from the largest chest hospital in Delhi.JDMS.2013;3(6):4651.

13. Mohanty S, Kapil A, Das BK. Bacteriology of parapneumonic pleural effusions in an Indian hospital. Trop Doct I.2007;37(4):228-29.

14. Ferrer A, Osset J, Alegre J, Surinach JM, Crespo E, Fernandez de SevillaT et al.

Prospective clinical and microbiological study of pleural effusion. Microbiolo Infect Dis. 1999;18(4):237-41.

15. Falguera M, Carratal J, Bielsa S. Predictive factor, microbiology and outcome of patients with parapneumonic effusion. Eur Respir J.2011;38:117379.

16. Marinkovic SP, Topuzovska IK, Milenkovic Z, Kondov G, Anastasovska A. Clinical Laboratory and Radiographic features of patients with pneumonia and parapneumonic effusions. 2016;4(3):428-34. 